\title{
Analgesic effect of indomethacin shown using the nociceptive flexion reflex in humans
}

\author{
R Guieu, O Blin, J Pouget, G Serratrice
}

\begin{abstract}
This study investigated whether indomethacin has an analgesic effect on the central nervous system. As analgesics which affect the central nervous system produce a correlated decrease in the subjective sensation of pain and in the nociceptive reflex in humans, the amplitude of the nociceptive flexion of the biceps femoris was studied. Eight patients (six men, two women) aged 35-70 years (mean 51) with rheumatic diseases were included in the study. Each patient was his or her own control and was given a single intramuscular injection of either $50 \mathrm{mg}$ of indomethacin or a placebo. A placebo controlled, double blind experimental design was used. Patients were evaluated before and 30,60 , and 75 minutes after the injection. Seventy five minutes after injection, indomethacin gave a $54 \%$ decrease in the amplitude of the nociceptive reflex, whereas the placebo produced a decrease of only $12 \%$. This suggests that indomethacin exerts a depressive effect on the amplitude of the nociceptive reflex and affects the central nervous system as part of its analgesic action.
\end{abstract}

In addition to their anti-inflammatory properties, an analgesic effect has been found for aspirin-like drugs, ${ }^{1}$ diclofenac, ${ }^{2}$ and ketoprofen. ${ }^{3}$ Indomethacin is used for the treatment of rheumatoid diseases ${ }^{46}$ and has also been successful in combating pain in adults after operations. ${ }^{78}$ Indomethacin allows the dose of morphine given to children after operations to be reduced. ${ }^{9}$ In healthy volunteers, indomethacin increases the threshold of electrically induced pain, as assessed on a visual analogue scale. ${ }^{10}$

Any analgesic effect of anti-inflammatory drugs is conventionally ${ }^{11}$ regarded as resulting from a peripheral mechanism which has been shown in animals. ${ }^{12}{ }^{13}$ The assumed underlying mechanism is the prevention of prostaglandin generation in peripheral inflamed tissues ${ }^{14}$ is which can sensitise the peripheral terminals of primary afferent nociceptors. ${ }^{1}{ }^{16}$

Animal studies also indicate that prosta-

Clinique des

Maladies du Système

Nerveux et de l'Appareil

Locomoteur,

CHU Timone, F-13385

Marseille Cedex 5,

France

R Guieu

O Blin

J Pouget

G Serratrice

Correspondence to:

Dr Blin.

Accepted for publication 29 May 1991 effect remains controversial, however.

The aim of this study was to investigate the potential analgesic effect on the central nervous system of indomethacin in humans. This analgesic effect was assessed by electrophysiological methods. The nociceptive flexion reflex of the leg (RIII) was used because it is a useful and objective tool for the assessment of human pain. It is correlated with the sensation of pain and is depressed by central nervous system analgesics such as morphine or its derivatives. ${ }^{18} 19$

Patients and methods PATIENTS

Eight patients (six men, two women) aged 35-70 years (mean 51) took part in the study after clinical and biological examination. All had chronic pain (lower back pain or lumbosciatica). None had any history of allergy or gastroduodenal ulcers and none showed peripheral neuropathy or cutaneous lesions of the legs. All patients gave fully informed consent and the approval of the local ethics committee was obtained.

\section{TREATMENT}

All treatment with analgesics was stopped at least 48 hours before the study. The drugs studied were indomethacin $(50 \mathrm{mg})$ and a placebo (saline). Intramuscular injections $(2 \mathrm{ml})$ were given.

\section{EXPERIMENTAL DESIGN}

Each subject was his or her own control and was given the treatment at $4 \mathrm{pm}$ in a double blind, cross over design. At least 48 hours were left between the treatments to ensure washout of the drug.

\section{ASSESSMENT}

A Racia's algometer including a constant current electrical stimulator with variable intensity, pulse width and rate, was used. Each patient sat in a comfortable armchair in a room at constant temperature $\left(24^{\circ} \mathrm{C}\right)$. Transcutaneous electrical stimulation of the sural nerve was given with two surface electrodes placed on the degreased skin in the area of the external retromaleolar gutter. Stimulation was performed in successive series of five rectangular pulses lasting one millisecond at two millisecond intervals. The reflex activity was recorded electromyographically at the short part of the biceps femoris on the same side using a pair of surface electrodes. The electrodes were not removed for the entire duration of the test. In the patients with lumbosciatica, the contralateral side was tested. The reflex responses were full wave rectified, integrated, and were analysed 


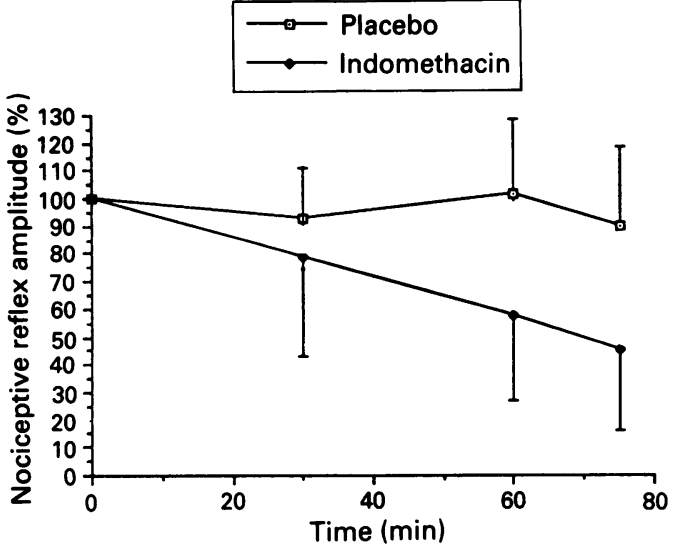

Variation in the amplitude of the nociceptive reflex (mean and standard deviation) in eight patients 30,60 , and 75 minutes after the intramuscular injection of indomethacin $(50 \mathrm{mg})$ or a placebo.

over 150 milliseconds (50-200 milliseconds window), amplified with a band pass of 10-1500 $\mathrm{Hz}$, with a gain of $240 \mu \mathrm{V}$ and an acquisition delay of 50 milliseconds. The electromyographic responses were digitised at $200 \mathrm{~Hz}$. The reflex threshold was conventionally defined as the smallest intensity of stimulus giving a probability of $100 \%$ for the RIII motor responses.

To determine the reflex threshold, the stimulation intensity was varied across three ascending and descending series. A series of 10 consecutive reflexes was then obtained using a suprathreshold intensity ( 1.3 times the threshold intensity) to determine the reproducibility. The average amplitude of these 15 reflexes was then calculated before injection and at 30, 60, and 75 minutes after injection.

\section{STATISTICAL ANALYSIS}

The effects of the injections were assessed by an analysis of variance using VAR3 software with two between subject factors (subjects and drugs) and one within subject factor (time) as the main source of variation.

\section{Results}

The figure shows that compared with the placebo, indomethacin gave a decrease in the nociceptive flexion activity; after 75 minutes the decrease was $12 \%$ for the placebo and $54 \%$ for indomethacin. The effect of the drug on the variation in the nociceptive reflex amplitude was significant $(F[1,7]=18.5, p<0.01)$. Analysis showed that there was a significant time effect with indomethacin $(F[2,14]=4.37, p<0.05)$ and that the effect of the drug on the nociceptive reflex was limited to 60 and 75 minutes $(F[1,7]=$ 33.8 and $19.3 ; p<0.001$ and $p<0.01$ respectively).

\section{Discussion}

This study indicates that indomethacin provides a significant depressive effect on the amplitude of the nociceptive reflex, and thus possesses an analgesic effect. This effect can be considered to originate in the central nervous system; the transcutaneous stimulation of the sural nerve does not involve the peripheral receptors. ${ }^{3}$ No evidence was found of a depressive action on the conduction of the peripheral nerve fibres after indomethacin was injected parenterally.

Indomethacin rapidly crosses the blood-brain barrier. It was detected in the cerebrospinal fluid after 30 minutes and a state of equilibrium was attained 1.6 hours after the intramuscular injection. The analgesic effect was not correlated with the concentration of indomethacin in either plasma or the cerebrospinal fluid. ${ }^{20}$ The mechanism of the analgesic effect of nonsteroidal anti-inflammatory drugs (NSAIDs) on the central nervous system remains unknown. Although indomethacin causes a decrease in the $\beta$ endorphin concentrations in plasma, no correlation has been found between the patient's perception of pain relief and concentrations of $\beta$ endorphin in plasma. ${ }^{4}$

The sites in the central nervous system that are responsible for the analgesic effect of NSAIDs probably differ from the site of action found for morphinic drugs. ${ }^{21}$ Several sites have been suggested: the preoptic anterior hypothalamus, as the injection of small amounts of aspirin into this structure induces analgesia ${ }^{22}$; the periaqueductus grey matter, as the injection of aspirin-like drugs reduces the nociceptive flexion reflexes ${ }^{23}$; and the thalamus, as aspirinlike drugs reduce the evoked nociceptive potential in the ventral nucleus of the thalamus. ${ }^{24}$

The analgesic effect of NSAIDs is thought to result from the inhibition of the synthesis of prostaglandins. Low doses of prostaglandins given intrathecally lower nociceptive thresholds, whereas low doses of NSAIDs given in the same way antagonise nociceptive effects induced peripherally. ${ }^{1325}$ Peripheral analgesia induced by NSAIDs is enhanced by simultaneous intracerebroventricular injection. ${ }^{13}$ Intrathecal injections of aspirin or indomethacin cause dose dependent hypoanalgesia in rats, and this effect is antagonised by the intrathecal injection of prostaglandin $E_{2}{ }^{26}$ We suggest that prostaglandins may act at the spinal terminals of brain stem noradrenergic neurones.

It has been suggested that the inflammatory, analgesic, and antipyretic properties of aspirinlike drugs cannot be dissociated as they all show evidence of the action of prostaglandin inhibitor. ${ }^{27}$ Ferreira et al suggested that the central component of hyperanalgesia can only be detected in the presence of an inflammatory process. ${ }^{13}$ Studies on healthy humans using the nociceptive flexion reflex have clearly shown that NSAIDs have an analgesic effect on the central nervous system that is independent of any inflammatory process. ${ }^{3}$ Furthermore, the anti-inflammatory and analgesic effects are dissociated. Indomethacin ( $2 \mathrm{mg} / \mathrm{kg}$ ) decreased pain but did not modify trypsin induced oedema. ${ }^{28}$ There is no significant correlation between the analgesic effect and the inhibition of the synthesis of prostaglandins. ${ }^{29}$ As shown for peripheral neurones, the analgesic effect could be related to the direct effect of the drug on the membrane potential. ${ }^{30}$

In addition to its peripheral analgesic effect, 
indomethacin has a component in its analgesic action which affects the central nervous system. A previous study of patients with a sectioned spinal cord suggests that NSAIDs exert this analgesic effect on the central nervous system principally at the supraspinal level. ${ }^{3}$ This analgesic effect is probably not only a result of the inhibition of prostaglandin activity. This property extends the potential scope of effectiveness of indomethacin. The presence of an analgesic effect on the central nervous system, first for ketoprofen, ${ }^{3}$ and now for indomethacin, questions the validity of the distinction between the so called peripheral and central analgesic drugs.

1 Ferreira S H. Prostaglandins, aspirin-like drugs and analgesia. Nature 1972; 200: 240-3.

2 Attal N, Kayser A, Benoist J M, Guilbaud G. Behavioral and electrophysiological evidence for an analgesic effect of nonsteroidal anti-inflammatory agent, sodium diclofenac. Pain 1988; 35: 341-8.

3 Willer J C, De Brouker T, Bussel B, Roby-Bramy A, Harrewyn J M. Central analgesic effect of ketoprofen in humans; electrophysiological evidence for a supra spinal mechanism in a double blind cross over study. Pain 1990; 38: 1-7.

4 Brandman S, Vandeburg M J, Jenkins R, Currie J C. The effect of non-steroidal anti-inflammatory therapy on plasma neuropeptide concentrations in patients with osteoarthritis. Br $\mathcal{F}$ Rheumatol 1985; 24: 46-52.

5 Vandenburg $M J$, Brandman S, Jenkins R, Currie W J C. The effect of non-steroidal anti-inflammatory therapy on plasma neuropeptide concentrations in patients with osteoarthritis. Br f Clin Pharmacol 1984; 17: 628-9.

6 Isomaki $\mathrm{H}$, Martio J, Kaarela J, et al. Comparison of the analgesic effect of ten nonsteroidal anti-inflammatory drugs. $B r \mathcal{F}$ Rheumatol 1984; 23: 61-5.

7 Keenan D J M, Cave K, Langdon L, Lea R E. Comparative trial of rectal indomethacin and cryoanalgesia for control of early postthoracotomy pain. $B M \mathcal{F} 1983 ; 287$ : 1335-7.

8 Mattila M A K, Ahlström-Bengs E, Pekkola P. Intravenous indomethacin or oxycodone in prevention of post-operative indomethacin or oxycodone in pre

9 Maunuksela E L, Oikkola K T, Korpela R. Does prophylactic intravenous infusion of indomethacin improve the management of post-operative pain in children? Can $\mathcal{F}$ Anaesth 1988; 2: 123-7.

10 Holland R L, Tan P, Peck A W, Telekes A. Dipipanone and indomethacin: effects on electrically induced pain in volunteers. British fournal of Clinical Pharmacodymamics volunteers. 25 : 118-9.

11 Besson J M, Boureau F, Chaouch A, et al. Les antalgiques.
In: Dehen H, Dordain G, eds. Neuropharmacologie Clinique. Paris: Doin, 1988: 126-32.

12 Lim R K S, Guzman F, Rodgers D W, et al. Site of action of narcotic and non-narcotic analgesics determined by blocking bradykinin-evoked visceral pain. Arch Int Pharmacodyn Ther 1964; 152: 25-58.

13 Ferreira S H, Berenice H, Lorenzetti B, Correa F M A. Central and peripheral anti-analgesic action of aspirin-like drugs. Eur F Pharmacol 1978; 53: 30-48.

14 Lim R K S. Pain. Annu Rev Physiol 1970; 32: 269-88.

15 Ferreira S H, Moncada S, Vane J R. Indomethacin and aspirin abolish prostaglandin release from the spleen. Nature 1971; 231: 237-40.

16 Ferreira S H, Moncada S, Vane J R. Prostaglandins and the mechanism of analgesia produced by aspirin-like drugs. $\mathrm{Br}$ f Pharmacol 1973; 49: 86-97.

17 Ramwell P W, Shaw J E, Jessup R. Spontaneous and evoked release of prostaglandins from frog spinal cord. $A m \mathcal{J}$ Physiol 1966; 211: 998-1004.

18 Willer J C. Nociceptive flexion reflexes as a tool for pain research in man. In: Desmedt J E, ed. Motor control mechanisms in health and disease. New York: Raven Press, 1983: 809-27.

19 Willer J C. Studies on pain. Effects of morphine on a spinal nociceptive flexion reflex and related pain sensation in man. Brain Res 1985; 331: 105-14.

20 Bannwarth B, Netter P, Lapiecque F, Pere P, Thomas P H, Gaucher A. Plasma and cerebrospinal fluid concentrations of indomethacin in humans. Eur 7 Clin Pharmacol 1990; 38: 343-8.

21 Okuyama S, Aihara $\mathrm{H}$. The site of action of morphine and indomethacin differ with electrical stimulation of cutaneous or tibial nerves in normal and adjuvant arthritis in rats. Arch Int Pharmacodyn Ther 1985; 276: 1433-1451.

22 Schady W, Torebjörk H E. Central effect of zomepirac on pain evoked by intraneural stimulation in man. 3 Clin Pharmacol 1984; 24: 429-35.

23 Carlsson K H, Helmereich J, Jurna I. Activation of inhibition from the periaqueductal grey matter mediates central
analgesic effect of metamizol. Pain 1986; 27: 373-90.

24 Carlsson K H, Monzel W, Jurna L. Depression by morphine and the non-opioid analgesic agents metamizol, lysine acetylate and paracetamol, of activity in rat thalamus neurons evoked by electrical stimulation of nociceptive afferents. Pain 1988; 32: 313-26.

25 Ferreira $\mathrm{S} \mathrm{H}$. Prostaglandins: peripheral and central analgesia. In: Bonica J J, Lindblom U, Iggo A, eds. Advances in pain research and therapy. New York: Raven Press, 1983: research
$627-34$.

26 Taiwo Y O, Levine J D. Prostaglandins inhibit endogenous pain central mechanisms by blocking transmission at spinal noradrenergic synapses. F Neurosci 1988; 8: 1346-9.

27 Vane J R. Inhibition of prostaglandin synthesis as a mechanism of action for aspirin-like drugs. Nature 1971; 231: 232-5.

28 Huskisson E C. Non narcotic analgesia. In: Wall P D, Melzack R, eds. Textbook of pain. Edinburgh: Churchill Livingstone, 1984: 503-15.

29 Ziel R, Krupp P. Significance of the membrane stabilization effect of non-narcotic analgesics. In: Bonica J J, AlbeFessard D, eds. Advances in pain research and therapy. Vol. 1. New York: Raven Press, 1976: 517-21.

30 Levitan H, Barker J L. Salicylate: a structure activity study on its effects on membrane permeability. Science 1972; 176: on its efi. 